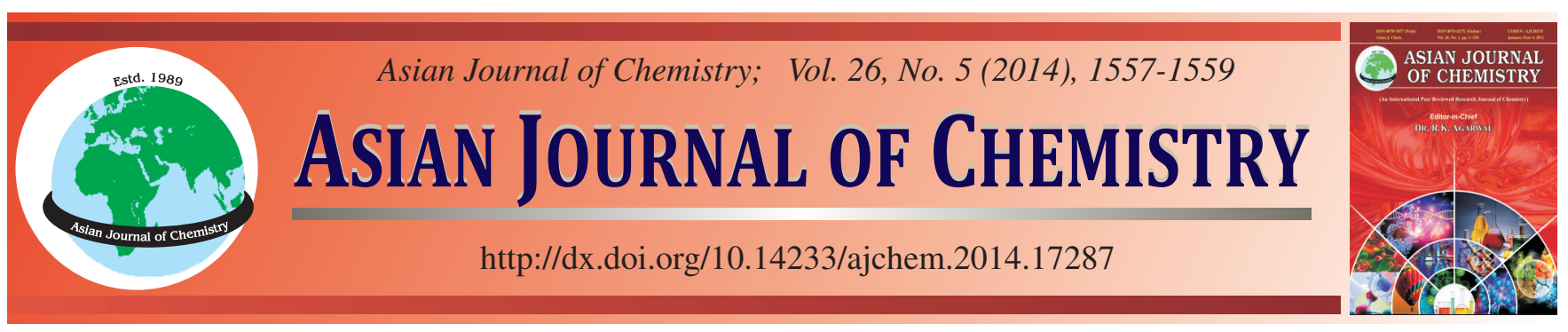

\title{
Synthesis of CIGS Powder by Mechanochemical Method $\dagger$
}

\author{
Sin-IL Gu ${ }^{1,2}$, Hyo-SoOn ShIN ${ }^{1}$, Dong-Hun YeO ${ }^{1, *}$ and SAHN NAHM ${ }^{2}$
}

${ }^{1}$ Advanced Materials Convergence Division, Korea Institute of Ceramic Engineering and Technology 233-5, Gasan-Dong, Guemcheon-Gu Seoul 153-801, Republic of Korea

${ }^{2}$ Department of Materials Science and Engineering, Korea University, Seoul 136-701, Republic of Korea

*Corresponding author: E-mail: ydh7@kicet.re.kr

To this day $\mathrm{CuIn}_{1-\mathrm{x}} \mathrm{Ga}_{\mathrm{x}} \mathrm{Se}_{2}$ (CIGS) powder used in the manufacture of thick-film CIGS photovoltaic (PV) cells was mainly produced using the solvothermal method. However, this method has drawbacks such as it is expensive and cannot be used to mass produce the CIGS powder. Thus, there is a need to develop a more cost-effective manufacturing process for mass production of CIGS powder to develop stable thick-film CIGS PV cells. The mechanochemical method, which facilitates mass production, can be considered as an alternative for the synthesis of CIGS, but such research results have yet to be reported. In this study, the CIGS synthesis pathway using the mechanochemical method was determined, through which single-phase CIGS was synthesized. Single-phase CIGS was synthesized when the molar ratio $\mathrm{x}$ of $\mathrm{Ga}$ was below 0.15 in the raw material, $\mathrm{CuIn}_{1-\mathrm{x}} \mathrm{Ga}_{\mathrm{x}} \mathrm{Se}_{2}$, but not above this ratio. Also, adding CGS to the CIGS synthesized using the mechanochemical method for a secondary synthesis resulted in increased proportion of Ga in CIGS. Based on the results, it was confirmed that CIGS powder could be synthesized in large quantities at a low cost using the simple process of milling.

Keywords: CuIn ${ }_{1-\mathrm{x}} \mathrm{Ga}_{\mathrm{x}} \mathrm{Se}_{2}$ powder, Mechanochemical method, Thick film process, Solar cell.

\section{INTRODUCTION}

There has recently been an increase of research on thickfilm $\mathrm{CuIn}_{1-\mathrm{x}} \mathrm{Ga}_{\mathrm{x}} \mathrm{Se}_{2}$ (hereafter CIGS) photovoltaic cell as it is easy and inexpensive to increase the area $^{1}$. In order to manufacture thick-film CIGS photovoltaic cells, there is a need to develop a process that makes it possible to manufacture CIGS powder in large quantities at low costs ${ }^{2}$. Thus, there has mainly been research on synthesizing CIGS powder applicable to the thickfilm process using the solvothermal method ${ }^{3,4}$. However, the solvothermal method has drawbacks in that it is costly and poses difficulties in mass production ${ }^{5}$. Thus, there is a need for another method that can be used to synthesize CIGS in an easier and more cost-effective manner.

The advantage of using the mechanochemical method is that it can synthesize powder in large quantities easily $y^{6,7}$. Thus, various types of powder have been synthesized using this method $^{8,9}$. The results of studies on synthesis of CIS, which is simpler than synthesis of CIGS, for the manufacture of thickfilm PV cells, have been reported by Wu et al. ${ }^{10}$ and Wada et $a l .{ }^{11}$. However, there have not been any results on synthesizing single-phase CIGS using the mechanochemical method.
The aim of this study was to synthesize the powder from the raw ingredients, $\mathrm{Cu}, \mathrm{In}, \mathrm{Ga}$ and $\mathrm{Se}$, using the mechanochemical method and to understand the CIGS synthesis pathway by analyzing the crystal structure and changing the processes. The ultimate aim was to synthesize single-phase CIGS powder in large quantities that can be applied to thickfilm PV cell using the results of the experiment.

\section{EXPERIMENTAL}

The powders of $\mathrm{Cu}(99.7 \%$, Sigma-Aldrich Co. Ltd., Japan), In (99.99 \%, Sigma-Aldrich Co. Ltd., Japan), Ga (99.99 $\%$, Sigma-Aldrich Co. Ltd., Japan) and Se (99.99 \%, SigmaAldrich Co. Ltd., Japan) were used. And the solvent was used diethylamine (99.9 \%, Sigma-Aldrich Co. Ltd., Japan).

In a glove box with nitrogenous atmosphere, $\mathrm{Cu}, \mathrm{In}, \mathrm{Ga}$ and Se powders, $60 \mathrm{~g}$ of $3 \Phi$ zirconia balls and $1.2 \mathrm{cc}$ of diethylamine were loaded into a $45 \mathrm{cc}$ zirconia jar. The molar ratio of In and $\mathrm{Ga}$ was varied during the experiment and the total amount of powder was $10 \mathrm{~g}$. For the zirconia jar, planetary mill (Pulverisette 7, Fritsch GmbH, Germany) was used to perform the milling process for $1 \mathrm{~h}$ at $300 \mathrm{rpm}$, after which the powder was dried for $24 \mathrm{~h}$ at $80^{\circ} \mathrm{C}$. 
In a glove box with nitrogenous atmosphere, the CIGS powder $(7.3 \mathrm{~g})$ synthesized in the primary synthesis process and the additional raw materials of $\mathrm{Cu}(0.192 \mathrm{~g}), \mathrm{Ga}(0.248 \mathrm{~g})$ and $\mathrm{Se}(0.519 \mathrm{~g})$ were weighed and loaded into a $45 \mathrm{cc}$ zirconia jar with $60 \mathrm{~g}$ of $3 \Phi$ zirconia balls and $1.2 \mathrm{cc}$ of diethylamine. For the zirconia jar, planetary mill was used to perform the milling process for $1 \mathrm{hr}$ at $300 \mathrm{rpm}$, after which the powder was dried for $24 \mathrm{~h}$ at $80^{\circ} \mathrm{C}$.

The crystal structures of synthesized powders were measured by X-ray diffractometer (PANalytical, X'pert pro, Netherlands) and the particle morphologies were observed by field emission scanning electron microscope (LSM-6700F, Jeol, Japan).

\section{RESULTS AND DISCUSSION}

Fig. 1 shows X-ray diffraction patterns of synthesized powder with composition of (a) $\mathrm{CuInSe}_{2}$, (b) $\mathrm{CuIn}_{0.5} \mathrm{Ga}_{0.5} \mathrm{Se}_{2}$ (c) $\mathrm{CuGaSe}_{2}$. Synthesis of CIS using the mechanochemical method produced single-phase CIS. Also, the results of the preceding experiment showed that the powder particle size could be controlled during CIS synthesis by adding a solvent ${ }^{12}$. However, in case of $\mathrm{CuIn}_{0.5} \mathrm{Ga}_{0.5} \mathrm{Se}_{2}$, in which $50 \%$ of In was substituted with $\mathrm{Ga}$, In and Se peaks were observed and $\mathrm{CuSe}_{2}$ was produced as shown in (b). As for $\mathrm{CuGaSe}_{2}$, where In was completely substituted with $\mathrm{Ga}$, no peaks were observed, while $\mathrm{CuSe}$ and unknown phases were observed. Based on these results, it was determined that during synthesis of CIGS powder using the mechanochemical method, an increase of Ga led to formation of phases that were not consistent with the added metal sources. This is thought to be caused by the fact that Ga, one of the raw materials, is in liquid form at room temperature and absorbs the shock between the balls during the milling process, thereby interfering with the synthesis. This result is consistent with the result of increasing the amount of solvent added during the synthesis of CIS powder, reported by $\mathrm{Gu}$ et al. ${ }^{12}$. Adding a small amount of solvent does not interfere with the synthesis of CIS and enhances the milling effect, whereas excess solvent absorbs shock and interferes with the synthesis of CIS. This reason also applies in this case as the $\mathrm{Ga}$ metal source is in its liquid phase during the reaction.

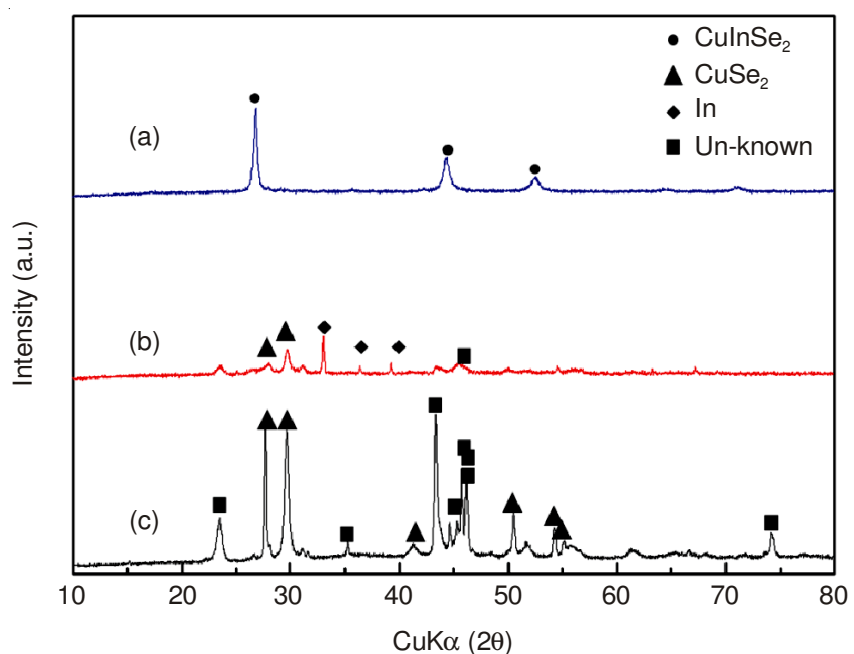

Fig. 1. X-Ray diffraction patterns of synthesized powder with composition of (a) $\mathrm{CuInSe}$, (b) $\mathrm{CuIn}_{0.5} \mathrm{Ga}_{0.5} \mathrm{Se}_{2}$ and (c) $\mathrm{CuGaSe}_{2}$
Thus, it was determined that a low molar ratio of Ga would not interfere with the reaction when synthesizing CIGS using the mechanochemical method. Fig. 2 shows the X-ray diffraction patterns of synthesized powder with the variation of $\mathrm{Ga}$ ratios of material source. Single-phase CIGS was synthesized until the molar ratio of Ga was 0.15 . However, when the molar ratio of Ga exceeded 0.2 , there was presence of $\mathrm{In}$, Se and $\mathrm{CuSe}$ without the synthesis of CIGS. Based on this, it was determined that adding a small amount of Ga does not interfere with the synthesis of CIGS, but adding an amount exceeding a particular ratio led to interference with the synthesis of singlephase CIGS.

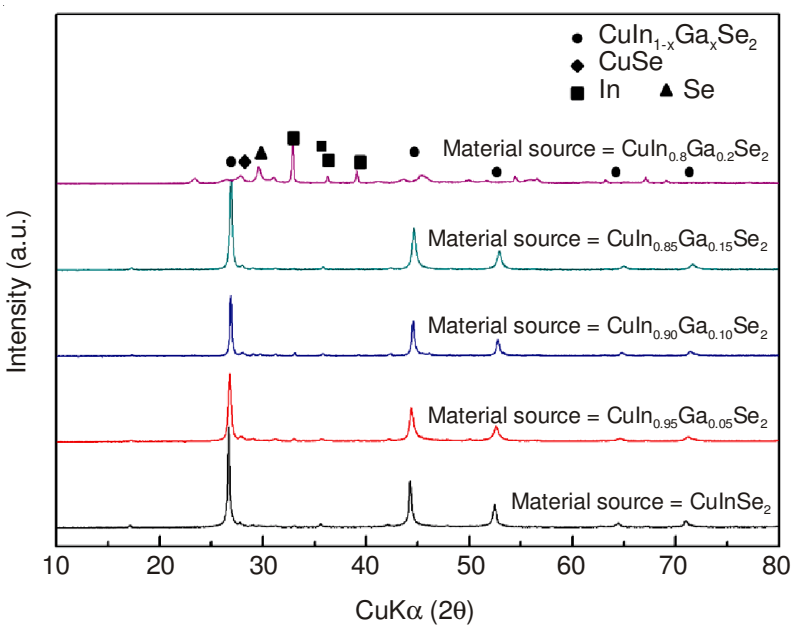

Fig. 2. X-Ray diffraction patterns of synthesized powder with the variation of $\mathrm{Ga}$ ratios of material source

Fig. 3 showed the Ga ratios of synthesized CIGS phase with the variation of Ga ratios of material source. Fig. 3 shows the Ga ratios of synthesized CIGS phase with the variation of $\mathrm{Ga}$ ratios of material source. Because the metal source, $\mathrm{Ga}$, is in its liquid phase at room temperature, observation is difficult through the X-ray diffraction pattern. Also, there is a need to check how much Ga has been incorporated into CIGS as it can exist as a mixture without being incorporated. The composition was checked based on the locations of the X-ray diffraction peaks using the synthesized CIGS powder and it showed that the proportion of $\mathrm{Ga}$ in the synthesized CIGS increased constantly with increasing proportion of $\mathrm{Ga}$ in the raw sources. In addition, based on the observation that the proportions of $\mathrm{Ga}$ in the raw sources and in the synthesized CIGS were consistent with each other, it was determined that all the Ga from the raw sources was incorporated into CIGS. From these results, it was determined that adding a small amount of $\mathrm{Ga}$ leads to $100 \%$ participation in the reaction without interfering with the synthesis of CIGS.

The efficiency of CIGS PV cell varies depending on the ratio of In and Ga in CIGS. The ratio of In and Ga in a CIGS $\mathrm{PV}$ cell, which is considered most efficient to this day, is $7: 3^{13}$. However, the molar ratio of $\mathrm{Ga}$ that can be incorporated into CIGS through one milling process is only 0.15 as confirmed in Fig. 3. Thus, $\mathrm{Cu}, \mathrm{Ga}$ and $\mathrm{Se}$ were added to the synthesized $\mathrm{CuIn}_{0.85} \mathrm{Ga}_{0.15} \mathrm{Se}_{2}$ for a secondary synthesis. Fig. 4 is the X-ray diffraction pattern of a) one time synthesis powder and (b) two time synthesis powder with the addition of CGS source. 


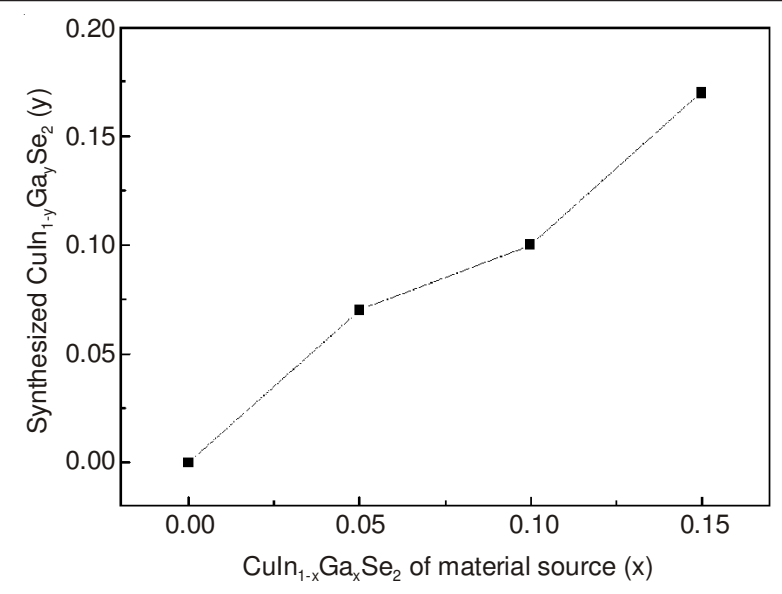

Fig. 3. Ga ratios of synthesized CIGS phase with the variation of Ga ratios of material source

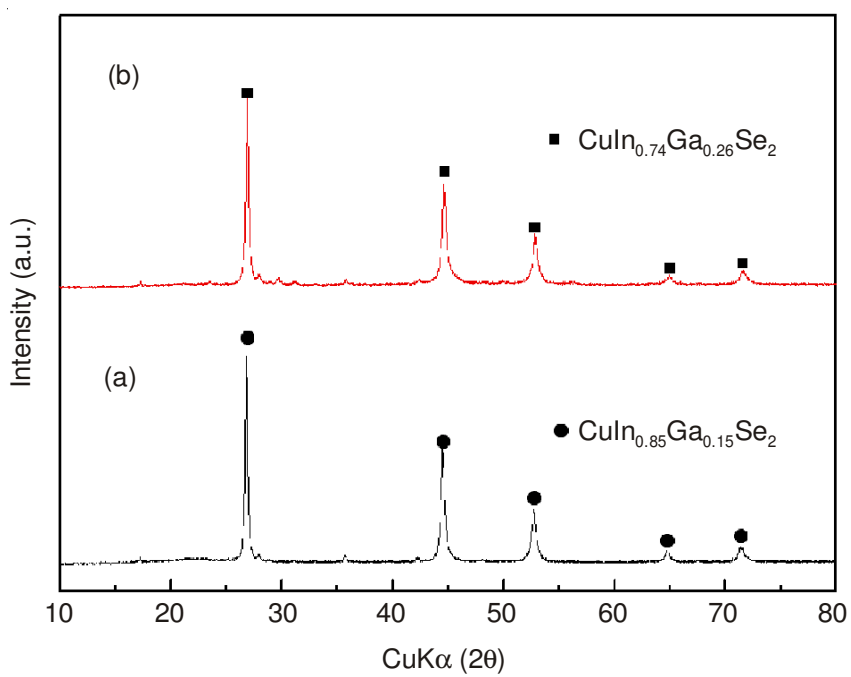

Fig. 4. X-Ray diffraction patterns of a) one time synthesis powder and (b) two time synthesis powder with the addition of CGS source

Adding the raw sources, $\mathrm{Cu}$, Ga and $\mathrm{Se}$, to the $\mathrm{CuIn}_{0.85} \mathrm{Ga}_{0.15} \mathrm{Se}_{2}$ produced after the primary synthesis resulted in the synthesis of $\mathrm{CuIn}_{0.74} \mathrm{Ga}_{0.26} \mathrm{Se}_{2}$. Through this, it was indirectly confirmed that it was possible for $\mathrm{Cu}, \mathrm{Ga}$ and $\mathrm{Se}$ to additionally be incorporated into the synthesized CIGS.

Fig. 5 shows the morphologies of (a) one time synthesis powder and (b) two time synthesis powder. The synthesized $\mathrm{CuIn}_{0.85} \mathrm{Ga}_{0.15} \mathrm{Se}_{2}$ varied greatly in size, from hundreds of $\mathrm{nm}$ to dozens of $3, \mathrm{CuIn}_{0.74} \mathrm{Ga}_{0.26} \mathrm{Se}_{2}$ synthesized through a secondary synthesis process also showed similar sizes. It was determined that there were no significant differences in the size between these two powders because milling was sufficiently performed in the first hour.
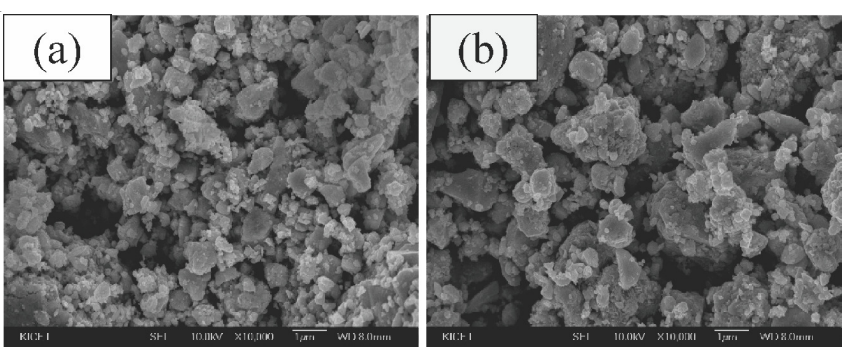

Fig. 5. Morphologies of (a) one time synthesis powder and (b) two time synthesis powder

\section{Conclusions}

The results of CIGS synthesis using the mechanochemical method with $\mathrm{Cu}, \mathrm{In}, \mathrm{Ga}$ and $\mathrm{Se}$ as the raw sources are as follows:

- Single-phase CIGS was only synthesized when the molar ratio of $\mathrm{Ga}$ in the raw source, $\mathrm{CuIn}_{1-\mathrm{x}} \mathrm{Ga}_{\mathrm{x}} \mathrm{Se}_{2}$, was less than 0.15 and all the Ga present in the raw source was incorporated into CIGS.

- By adding the raw sources, $\mathrm{Cu}, \mathrm{Ga}$ and $\mathrm{Se}$, to the synthesized $\mathrm{CuIn}_{0.85} \mathrm{Ga}_{0.15} \mathrm{Se}_{2}$, the amount of $\mathrm{Ga}$ incorporated into the synthesized CIGS was increased.

- The synthesized CIGS varied greatly in size and the CIGS powder synthesized secondarily by adding the raw materials of CGS had similar size variations and shapes.

\section{REFERENCES}

1. S.J. Ahn, K.H. Kim and K.H. Yoon, Colloids Surf. A, 313-314, 171 (2008).

2. S.J. Ahn, K.H. Kim, Y.G. Chun and K.H. Yoon, Thin Solid Films, 515, 4036 (2007).

3. S.I. Gu, H.S. Shin, D.H. Yeo, Y.W. Hong and S. Nahm, Curr. Appl. Phys., 11, S99 (2011)

4. Y.-G. Chun, K.-H. Kim and K.-H. Yoon, Thin Solid Films, 480-481, 46 (2005).

5. X. Zhang, H. Liu, W. He, J. Wang, X. Li and R.I. Boughton, J. Cryst. Growth, 275, e1913 (2005).

6. S. Ohara, H. Abe, K. Sato, A. Kondo and M. Naito, J. Eur. Ceram. Soc., 28, 1815 (2008).

7. T.D. Isfahani, J. Javadpour, A. Khavandi, R. Dinnebier, H.R. Rezaie and M. Goodarzi, Int. J. Refrac. Metals Hard Mater, 31, 21 (2012).

8. T. Rojac, O. Masson, R. Guinebretiere, M. Kosec, B. Malic and J. Holc, J. Eur. Ceram. Soc., 27, 2265 (2007).

9. S.I. Gu, H.S. Shin, D.H. Yeo and S. Nahm, Asian J. Chem., 24, 4213 (2012).

10. S. Wu, Y. Xue and Z. Zhang, J. Alloys Comp., 491, 456 (2010).

11. T. Wada and H. Kinoshita, Thin Solid Films, 480-481, 92 (2005).

12. S.I. Gu, H.S. Shin, D.H. Yeo, S. Nahm, J. Ceram. Process Res., (Submitted).

13. I. Repins, M.A. Contreras, B. Egaas, C. DeHart, J. Scharf, C.L. Perkins, B. To and R. Noufi, Prog. Photovolt. Res. Appl., 16, 235 (2008). 